\title{
Hacia otras economías. Críticas al paradigma dominante*
}

\author{
Raúl González Meyer y Howard Richards \\ (Compiladores)
}

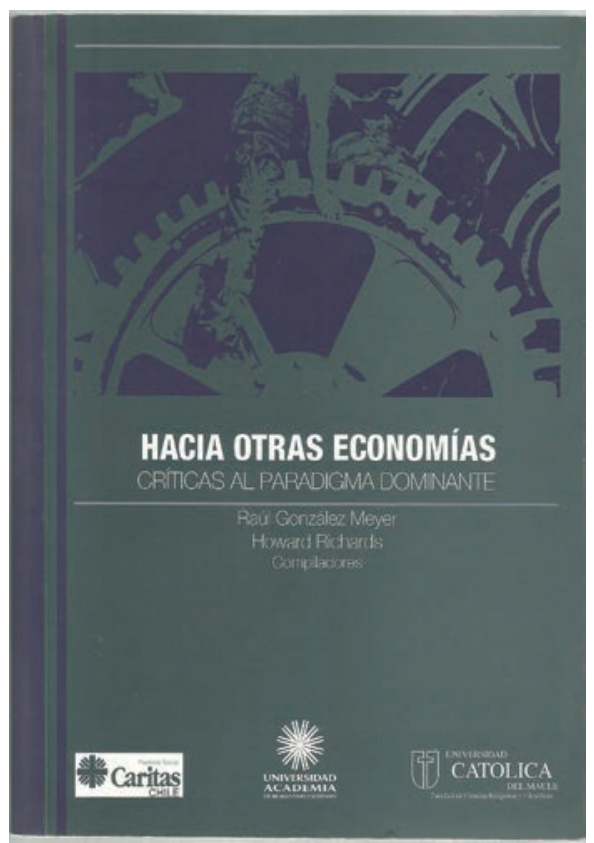

Juan Pablo Espinosa-Arce*

Los últimos años han estado dominados por la indignación frente a un modelo económico, político y social que parece estar desbaratándose. La conciencia de repensar nuestro posicionamiento en cada comunidad 
en la que nos desarrollamos, viene a sustentar esto de las "otras economías" que se construyen a partir de una crítica fundamentada en el paradigma dominante. El libro ${ }^{1}$ que presentamos tiene la particularidad de ser un trabajo conjunto entre seis economistas, cuatro filósofos, un antropólogo, un sociólogo, un ingeniero civil, un teólogo y un historiador, de manera de provocar un verdadero diálogo interdisciplinar en pos del replanteamiento de aquello que constituye para muchos el centro mismo del desarrollo de los países.

El libro está dividido en una introducción a cargo de los compiladores González y Richards, al que le siguen quince artículos divididos en cinco capítulos. Lo que se proponen los autores reunidos en el grupo de trabajo llamado Repensando la economía es asumir "la importancia de la contextualización del liberalismo económico y la ubicación de sus raíces precisas, lo que ayuda a mostrarlo como una construcción histórica" (p. 9). Al sostener que el modelo económico dominante es una construcción histórica se expresa un 'pacto social', el cual permite comprender que no es una realidad acabada, sino que, más bien, se está construyendo y deconstruyendo progresivamente, evitando así su ubicación como "racionalidad absoluta y fin de la historia" (p. 9). El objetivo central es, por tanto, la reflexión crítica y ética sobre los principios económicos del capitalismo, de manera de buscar alternativas que proporcionen un desarrollo más sustentable, especialmente en las luchas cotidianas de los más pobres, de los "marginados del sistema productivo y social" (p. 439).

En los artículos podemos identificar una concepción definida de lo humano, la cual se manifiesta en términos de prácticas solidarias, luchas populares por el desarrollo, reciprocidad o alternativas socioeconómicas ante la crisis. Estas categorías son levantadas desde los parámetros de la razón, de la política y de la ética, vistas como bases para pensar y reconstruir el orden social fundado en la justicia y la igualdad. Esto, a mi entender, resulta paradigmático porque responde a la recuperación de relatos de comunidades ubicadas en los márgenes, las cuales se oponen diametralmente al comportamiento egoísta, al lucro excesivo y acumulador, al pensar en el propio interés y no en el bien de la polisciudad. 
Esta "antropología fraterna" tiene el mérito de ser desarrollada no sólo por economistas, sino que también por filósofos y por teólogos, lo cual, a mi juicio, constituye un terreno aún necesario de explorar. Así encontramos los artículos del filósofo Pablo Salvat, en donde se desarrollan los conceptos de identidad, de la legitimidad del discurso del paradigma económico imperante, y de la búsqueda de nuevas consideraciones ético-políticas para reconstruir una economía que no consideraba a los "excluidos y postergados de este país, del continente y el mundo" (p. 97). O también la palabra del teólogo, P. César Carbullanca, quien, por medio de categorías bíblicas y teológicas, reconoce que el diálogo fe cristiana-política resulta una tarea ineludible para los creyentes. Se hace necesario, pues, un compromiso efectivo tanto en la vivencia de la fe, como en la reflexión teológica que asuma las voces silenciadas de los pobres.

A nivel de lo propiamente económico se presentan las teorías de Friedrich von Hayek, Premio Nobel de Economía en 1974, quien aporta nuevas alternativas para la organización de los grupos humanos a partir de una ética económica bien entendida, la cual "nos orienta a vivir cada vez más según normas más exigentes, más solidarias, más ecológicas” (p. 140). Es interesante la consideración de lo ecológico, ya que el paradigma dominante ha desconocido muchas veces el impacto del avance económico en detrimento de un ambiente sustentable. Actualmente ha aparecido una concepción bio-céntrica o eco-céntrica de la realidad, la cual supone el respeto por aquello que constituye nuestra casa común.

Otro de los teóricos de la economía que son presentados en la obra es Karl Polanyi, economista húngaro-americano que habla de que otra economía sigue siendo posible. Polanyi define la economía como "un proceso de interacción de los hombres entre sí y con la naturaleza, cuyo resultado es la provisión continua de medios materiales que permitan la satisfacción de las necesidades" (p. 349). Volvemos, pues, a presenciar la consideración de la naturaleza. Los grupos humanos, para el autor, están continuamente integrándose por medio de lazos y pactos sociales que aseguran la producción, la distribución o el consumo de los medios elaborados. Con esto los acuerdos económicos deben ser procesados "por una democracia participativa y no por un poder político de élites" (p. 356).

Pensar la economía en clave popular, es decir, considerando la participación efectiva y no sólo representativa de los integrantes de 
un determinado grupo humano, proporciona a la realidad elementos de interpretación que vienen a sacudir las bases de un sistema que en algún momento se había levantado como un "dios" que regía los destinos de los hombres y de las mujeres. El paradigma dominante que los autores critican desde sus respectivas áreas reflexivas es uno que, ideológicamente, es hegemónico, pero frente al cual consideran que es necesario integrar elementos de una economía social que llega a reconocer las legítimas diferencias de producción "de las sociedades andinas y mesoamericanas, las caribeñas o las del Cono Sur" (p. 357).

De esta manera, la obra Hacia otras economías. Críticas al paradigma dominante representa un esfuerzo conjunto de exponer la realidad económica actual por medio de una pedagogía clara, provocativa y que llama a la urgencia. Es, finalmente, una invitación a la unificación de fuerzas sociales que permitan repensar la relación del sistema político, social y económico, para que éstos dialoguen con la naturaleza y consideren la presencia de las comunidades que están al margen de los grandes acuerdos de las naciones. Sólo así podremos afirmar que otras economías siguen siendo posibles. 